\title{
ROBUSTNESS OF RULE SETS USING VHR IMAGERY TO DETECT INFORMAL SETTLEMENTS - A CASE OF MUMBAI, INDIA
}

\author{
V. Naorem ${ }^{\text {a }}$, M. Kuffer ${ }^{\text {a* }}$, J. Verplanke ${ }^{\mathrm{a}}$ and D. Kohli ${ }^{\mathrm{a}}$ \\ ${ }^{\text {a }}$ Faculty of Geo-Information Science and Earth Observation (ITC), University of Twente, PO Box 217, 7500AE Enschede, The \\ Netherlands - (v.naorem, m.kuffer, j.verplanke, d.kohli)@utwente.nl
}

KEY WORDS: informal settlements, slum ontology, robustness, rule set, OBIA, Mumbai, India

\begin{abstract}
:
Robust monitoring approaches for informal settlements using very high-resolution (VHR) satellite imagery can deliver essential information for supporting the formulation of pro-poor policies. Such information can complement census methods or participatory approaches. With the increasing availability of VHR satellite imagery, detection of the informal settlements benefits from the conceptualization of location-specific knowledge in the form of a locally-adapted generic slum ontology (GSO). In this study, we developed the local slum ontology for Mumbai, India, by incorporating local knowledge with image-based proxies. Then, we translated the local ontology into a rule set using Object Based Image Analysis (OBIA) to identify informal settlements by using spectral, spatial, geometric and texture measures. The method was applied to three subsets of a Worldview- 2 imagery. The robustness of the initial rule set was analysed with the help of membership functions. The results showed that the normalized difference ratio of near infrared (NIR) and blue band and grey level co-occurrence matrix (GLCM) features are most effective in all three subsets in the identification of informal settlements. The results suggest that the rule sets developed in this study can potentially be applied to other study areas of Worldview-2 imagery for informal settlements identification.
\end{abstract}

\section{INTRODUCTION}

\subsection{General Instructions}

The rapid growth of informal settlements in cities of the Global South is a cause of concern to local governments and a challenging task for the overall development of countries. On one hand, rapidly growing cities have high demand for workers in constructing infrastructures, retail and many other sectors. On the other hand, inhabitants of rural areas are attracted to cities because of employment and education opportunities and the general hope for improved living conditions. However, the high cost of living in formal areas and other social factors makes them to settle in informal areas commonly characterized by overcrowded, dilapidated housing and inadequate access to basic services (UN-Habitat, 2010). Moreover, locations of informal settlements are often at polluted and hazardous spots, e.g. areas close to rivers and places of unhygienic environment (Kit, Lüdeke, \& Reckien, 2012; Kohli, Sliuzas, Kerle, \& Stein, 2012; Kuffer, Pfeffer, \& Sliuzas, 2016). Eventually, all these factors severely affect the health conditions of the inhabitants of informal settlements(Subbaraman et al., 2014). As an initial step to tackle these problems in a decisive and effective manner there is a need to detect the location, boundaries and growth dynamics of informal settlements. This may provide important base data for planning and decision making to the concerned authorities. Allowing monitoring of development dynamics can assist in pro-poor policy formulation, as stepping stone towards inclusive development.

\subsection{Remote sensing for mapping informal areas}

Several methods like census methods, participatory mapping and advanced image analysis have been used to identify informal settlements. However, the utility of the census method is limited by the long temporal gap between two census surveys (Ebert, Kerle, \& Stein, 2009). Also, many settlements are not included in a census as they are not officially recognised (Nolan, 2015). The degree of the data aggregation can also be a problem (Kohli et al., 2012). Participatory mapping methods provide very rich ground information allowing incorporation of spatial and non-spatial data but are very time-consuming in large areas (Kohli et al., 2012). VHR images can help to outline informal settlements even in very heterogeneous areas and allow frequent mapping due to a high temporal resolution, which is of particular relevance for fast growing cities (Netzband \& Rahman, 2009 ).

OBIA has been successfully used in several studies to identify informal settlements in a fast and efficient way (e.g. Hofmann, Strobl, Blaschke, \& Kux, 2008; Kohli, Stein, Sliuzas, \& Kerle, 2015). Kohli et al. (2012) introduced the generic slum ontology (GSO) which defines the general characteristics of informal settlements and can be adapted and extended for operational tasks. The GSO supports the conceptualization of informal settlement characteristics for the creation of OBIA rule sets. However, one of the main limitations of OBIA is the robustness and transferability of rule sets across space and time. Rule sets commonly require extensive manual adaptation to obtain comparable results when applied to other images (even of the same city) (Hofmann, Blaschke, \& Strobl, 2011; Kohli, Warwadekar, Kerle, Sliuzas, \& Stein, 2013). Hofmann et al. (2011) defined robustness as the ability to generate comparable results on similar images with minimum adaptations. According to Hofmann (2014), robustness can be quantified by two factors, i.e., classification quality and deviation of the rule set, while five main deviations of the rule set exists:

- $\quad$ addition or removal of classes

- addition or removal of rules

\footnotetext{
* Corresponding author
} 
- changing logical operators

- changing relational operators

- changing the thresholds

Very few studies exist that focus on measuring the robustness of rule sets for mapping informal settlements. Thus there is a need to find the most robust features for mapping informal settlements. This study contributes in this direction by presenting a case of Mumbai, India.

\section{METHODOLOGY}

\subsection{Study area}

The study area in Mumbai, India has an urban population of 18.4 million according to the Indian Census 2011 (Government of India, 2015). The acquired WorldView-2 images (Pan: $0.5 \mathrm{~m}$ and Multispectral: $2 \mathrm{~m}$ ) covers the area surrounding the airport which contains large settlements (Figure 1) which have the typical features of informal settlements: small building size, high building density, organic pattern and diverse roof materials (Kuffer, Pfeffer, Sliuzas, \& Baud, 2016). Three subsets were chosen based on local knowledge to cover different morphologies and patterns, for instance, variability of shape and configuration.

- Subset 1 covers vegetation, river, formal buildings and Dharavi, which is known to be a large informal settlement.

- Subset 2 covers a mix of several informal and formal settlements.

- Subset 3 contains a mixture of vegetation, informal settlements located mainly close to old factories.

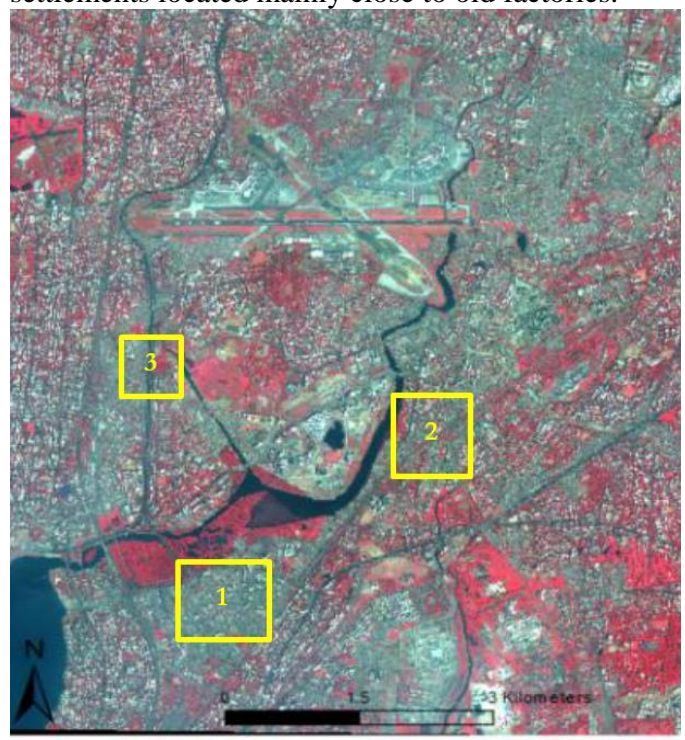

Figure1. Location of subsets (WorldView-2 image 2009)

Fieldwork was conducted in 2015. 150 ground control points were collected within the subsets using quota sampling.

\subsection{General Methodology}

Before performing OBIA, radiometric correction was conducted to ensure that the analysis was not much influenced by difference in atmospheric conditions using the FLAASH tool (Jinguo \& Zheng, 2008). For the translation of ontology and the development of rule sets, image analysis was done in two steps: segmentation and OBIA. The general overview of the methodology is given in Figure 2, details are explained in the following subsections.

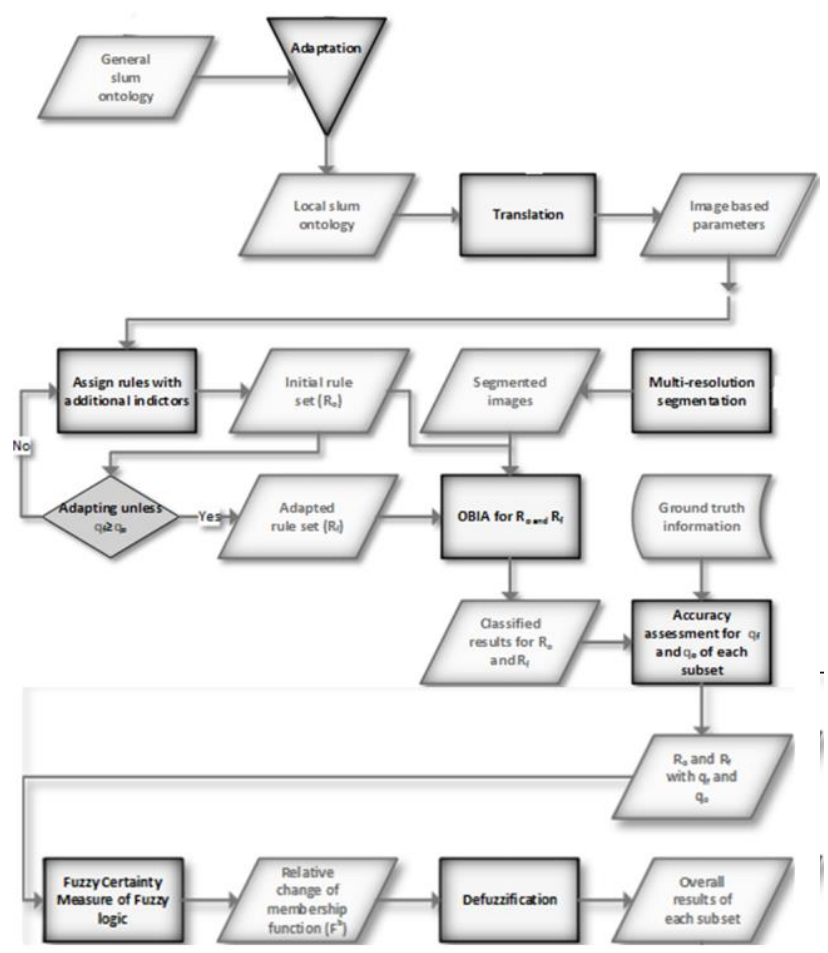

Figure 2. Overview of the methodology

\subsection{Development of the Local Ontology}

The local ontology describes the local features of informal settlements mainly based on morphological features (Kohli et al., 2012). A local ontology always needs to be developed since the GSO cannot be used for translating the image based parameters for classification directly. For this purpose, commonly expert knowledge is required. After obtaining local knowledge via a questionnaire from local experts, the main morphological indicators were conceptualized. These main indicators contributed to translate the local slum ontology into image based parameters. The local characteristics of informal settlements from the experts were organized according to the six general indicators given in GSO that are grouped at three spatial levels (i.e. object level, settlement and environs level).

\subsection{Image segmentation}

Before segmentation, the estimated scale parameter (ESP) tool for multiresolution segmentation was used to calculate the optimal scale parameter (Drăguț, Tiede, \& Levick, 2010). The tool measures the changing aspects of local variance (LV) from an object level to another so that the suitable scale parameter can be generated using rate of change (ROC):

$R O C=\left[\frac{L-(L-1)}{L-1}\right] * 100$

where $\quad \mathrm{L}=\mathrm{LV}$ at target level and

$$
\mathrm{L}-1=\mathrm{LV} \text { at next lower level. }
$$

In order to measure the segmentation quality of the study, we used the location discrepancy of a segmented object to a referenced object (Montaghi, Larsen, \& Greve, 2013), using forty manually delineated image objects for the assessment: 
$D_{s r}=\frac{1}{n} \sum_{i=0}^{n} \sqrt{\left(X_{s(i)}-X_{r}\right)^{2}+\left(Y_{s(i)}-Y_{r}\right)^{2}}$

where $D_{\text {sr }}$ is the average of the distance in the Euclidian plane between the centroid coordinates of the $\mathrm{i}^{\text {th }}$ segmented object $(\mathrm{Xs}(\mathrm{i})$ and $\mathrm{Ys}(\mathrm{i}))$ and the centroid coordinates of the reference object $\left(\mathrm{X}_{\mathrm{r}}\right.$ and $\left.\mathrm{Y}_{\mathrm{r}}\right)$.

When $\mathrm{D}_{\text {sr }}$ tends to be zero, the quality of the segmentation increases whereas increase of the $D_{\text {sr }}$ values represents underand over-segmentation.

\subsection{Classification}

The image based parameters were used for the development of the initial rule set to perform the classification of subset 1 . Each parameter was assigned with threshold values in the membership function of the class description. The class description was used for the classification of the image objects. Using the rule sets, we executed OBIA by employing the initial rule set for subset 1 as well as for subset 2 and subset 3 . Rule sets for subset 2 and subset 3 were adapted until a similar classification quality was achieved. The classification comprised of several hierarchical steps to extract the class features, i.e. vegetation, bare soil, roads, formal settlements, water, shadow and informal settlements in all 3 subsets. First, the class features vegetation, roads, water and shadow were classified. Second, formal settlements were classified followed by bare soil classification. Once all other classes were classified, the remaining objects were assigned to the class "informal settlements". The following parameters were used in all the three subsets for classification:

- $\quad$ Normalized difference green and red edge (NDGR) (used to separate bare soil and formal settlement areas) $\frac{\text { Green-Red edge }}{\text { Green+Red edge }}$ (Hamedianfar \& Shafri, 2015)

- $\quad$ Normalized difference NIR1 and blue (NDNB) (used to extract shadows) $\frac{\text { Blue-Near InfraRed }}{\text { Blue+Near InfraRed }}$ (Hamedianfar \& Shafri, 2015)

- Brightness (used to distinguish the formal areas)

- $\mathrm{GLCM}_{\mathrm{red}}$ entropy (used to distinguish formal and informal areas)

- $\quad$ NDVI (used to classify vegetation)

- GIS layers from open street maps (OSM) (used to classify roads and water).

Fuzzy rule sets were used to give membership values to each object of a class. To quantify the value of the relative deviation of feature parameters, a curve, the membership function, has been assigned to each parameter.

\subsection{Accuracy Assessment}

For this purpose ground truth information as well as manually generated reference data through visual interpretation were used. A sample of 35 points for informal settlements and 15 points for formal settlements were collected during the fieldwork. 25 additional points for water class features were used. The manual points were cross-checked with Google Earth imagery also referring to the ground points which have similar ground truth information. As per Lee, Shan, \& Bethel (2003), the mathematical equation of the quality percentage is the following:

$$
\begin{aligned}
& \text { Completeness }=\frac{T P}{(T P+F N)} \\
& \text { Correctness }=\frac{T P}{(T P+F P)} \\
& \text { Quality Percentage }=100 \times \frac{T P}{(T P+F P+F N)}
\end{aligned}
$$

where TP; FP and $F N$ are True Positive, False Positive and False Negative respectively.

\subsubsection{Robustness Measurements}

The measurement of the robustness of a rule set was adopted from Hofmann et al. (2011). The assessment of robustness uses two steps. First, the classification quality without adaption is assessed between the subsets. Achieving a similar quality without adaption is considered robust. Second, when adaption is required, the rule set is adapted until a quality comparable to subset 1 is achieved. Here a deviation the membership function $\delta \mathrm{F}$ was considered as the measurement of robustness. Hence the classification qualities for subset 2 and subset 3 were first compared with the quality of subset 1 . The quality for all three subset was measured on the basis of manually delineated settlements by local experts during the questionnaire.

The equation by Hofmann et al., (2011) gives the relative change of the adapted rule set:

$$
\delta \mathrm{F}_{i}=\delta \mathrm{a}_{i}+\delta \mathrm{v}_{i}
$$

where $\delta F_{i}$ is the relative change of a fuzzy membership function in the $\mathrm{i}^{\text {th }}$ subset

$\delta \mathrm{a}_{\mathrm{i}}$ is the relative change for shifts in the $\mathrm{i}^{\text {th }}$ subset $\delta v_{i}$ is the relative change for stretch or compression in the $\mathrm{i}^{\text {th }}$ subset

The following equation by Hofmann et al., (2011) measures the robustness of a particular rule set:

$$
r_{i}=\frac{q_{i} / q_{o}}{d+1}
$$

where $r_{i}$ is the robustness of the rule set in the $i^{\text {th }}$ subset, $\mathrm{d}$ is the sum of all rule set deviation,

$q_{i}$ is the quality of classification of test imagery ( $\left.\mathrm{I}_{\mathrm{f}}\right)$ using the rule set $\left(\mathrm{R}_{\mathrm{f}}\right)$; $\mathrm{q}_{\mathrm{o}}$ is the quality of classification of referenced imagery (Io) using the rule set $\left(\mathrm{R}_{\mathrm{o}}\right)$.

\section{RESULTS}

\subsection{Local Ontology}

The feature characteristics of informal settlements are summarised in the table 1 . This information was used for conceptualising the local knowledge of informal settlements and completing the set of indicators for the image based parameters. The overall feature types (quantitative indicators) for classification were spectral values, geometry and textural association. 
Table 1: Local ontology of informal areas in Mumbai

\begin{tabular}{|c|c|c|c|c|}
\hline Level & $\begin{array}{l}\text { General } \\
\text { indicators }\end{array}$ & $\begin{array}{l}\text { Image } \\
\text { domain }\end{array}$ & $\begin{array}{l}\text { Real world domain } \\
\text { (experts) }\end{array}$ & $\begin{array}{l}\text { Image based } \\
\text { parameters for } \\
\text { rule set }\end{array}$ \\
\hline \multirow[t]{2}{*}{ Environs } & $\begin{array}{l}\text { Site location } \\
\text { (hazards) }\end{array}$ & $\begin{array}{l}\text { Slope, } \\
\text { pattern, } \\
\text { secondary } \\
\text { data }\end{array}$ & $\begin{array}{l}\text { Waterlogging, along } \\
\text { railway lines, } \\
\text { proximity to high } \\
\text { voltage power lines }\end{array}$ & $\begin{array}{l}\text { Association - } \\
\text { distance to features }\end{array}$ \\
\hline & $\begin{array}{l}\text { Neighbourhood } \\
\text { characteristics }\end{array}$ & $\begin{array}{l}\text { Pattern, } \\
\text { secondary } \\
\text { data }\end{array}$ & $\begin{array}{l}\text { Often located in } \\
\text { between well- } \\
\text { developed areas, } \\
\text { close to employment }\end{array}$ & $\begin{array}{l}\text { Association - } \\
\text { distance to planned } \\
\text { areas and } \\
\text { employment } \\
\text { opportunities }\end{array}$ \\
\hline \multirow[t]{3}{*}{\begin{tabular}{|l|}
$\begin{array}{l}\text { Settlement } \\
\text { level }\end{array}$ \\
\end{tabular}} & $\begin{array}{l}\text { Density and } \\
\text { compactness }\end{array}$ & Pattern & $\begin{array}{l}\text { Highly compact } \\
\text { compared to planned } \\
\text { areas }\end{array}$ & $\begin{array}{l}\text { Association- } \\
\text { distance to less } \\
\text { compact areas }\end{array}$ \\
\hline & \multirow[t]{2}{*}{$\begin{array}{l}\text { Shape of the } \\
\text { settlement }\end{array}$} & \multirow[t]{2}{*}{ Texture } & $\begin{array}{l}\text { Planned areas with } \\
\text { medium density and } \\
\text { very dense irregular } \\
\text { layouts }\end{array}$ & Texture - entropy \\
\hline & & & $\begin{array}{l}\text { Lack of visibility of } \\
\text { road network and low } \\
\text { vegetation }\end{array}$ & $\begin{array}{l}\text { Geometry - area of } \\
\text { vegetation, service } \\
\text { area of road } \\
\text { network }\end{array}$ \\
\hline \multirow[t]{6}{*}{$\begin{array}{l}\text { Object } \\
\text { level }\end{array}$} & \multirow{3}{*}{\begin{tabular}{|l|}
$\begin{array}{l}\text { Characteristics } \\
\text { of building } \\
\text { structure }\end{array}$ \\
\end{tabular}} & Shape & Rectangular & $\begin{array}{l}\text { Geometry - } \\
\text { rectangular }\end{array}$ \\
\hline & & Size & $10-30 \mathrm{~m}^{2}$ & Geometry - area \\
\hline & & Material & $\begin{array}{l}\text { Iron, abestos, plastics, } \\
\text { concrete }\end{array}$ & \begin{tabular}{|l|}
$\begin{array}{l}\text { Spectral - layer } \\
\text { mean values }\end{array}$ \\
\end{tabular} \\
\hline & \multirow{3}{*}{\begin{tabular}{|l|} 
Road network \\
(type and nature \\
of roads)
\end{tabular}} & Shape & Irregular & $\begin{array}{l}\text { Geometry - } \\
\text { rectangular }\end{array}$ \\
\hline & & Type & $\begin{array}{l}\text { Unpaved, concrete, } \\
\text { tarmac (metalled), } \\
\text { Paved }\end{array}$ & $\begin{array}{l}\text { Spectral - } \\
\text { length/width ratio, } \\
\text { layer mean value }\end{array}$ \\
\hline & & Widths & $1-2 m^{2}$ & Geometry - area \\
\hline
\end{tabular}

\subsection{Image segmentation quality}

Multiresolution segmentation in eCognition 9.0 was employed. A value of 0.5 was used for shape and compactness. Calculating $\mathrm{D}_{\text {sr }}$ (equation 2) we obtained the following results:

$$
\begin{array}{ll}
\text { - } & \text { subset } 1 \text { is } 4.97 \text { metres } \\
\text { - } & \text { subset } 2 \text { is } 3.81 \text { metres } \\
& \text { subset } 3 \text { is } 3.99 \text { metres }
\end{array}
$$

The results of $D_{\text {sr }}$ indicate an acceptable segmentation quality. Problems are particularly caused by informal settlements forming groups of buildings in many segmented objects because of high densities, while in formal settlements, individual buildings and trees can be extracted. Integration of thematic layers of roads helped in segmentation.

\subsection{Classification and Accuracy Assessment}

After preforming the classification of subset 1 (Figure 3), the classification accuracy was assessed by calculating the overall accuracy using the standard error matrix. The classification accuracy for subset 1 was $87 \%$ (Kappa: 0.85). Best performing classes in subset 1 were vegetation, water and roads, with above $90 \%$ accuracies. Formal settlements were classified by using the combination of three parameters, namely GLCM, NDNB and brightness. Formal settlements were classified with lower accuracy (76\%), showing some mix-up with the classes bare soil and informal settlements. However, working with fuzzy membership function improved the performance of the classification of formal settlements. Bare soil was also classified with a relatively low accuracy of $72 \%$, due to similar spectral values of old roof materials and soil. Lastly, the remaining unclassified features were assigned as informal settlements and were classified with an accuracy of $72 \%$. We found that the parameters area and height, derived from digital elevation model (DEM), refined the classification because these parameters could be used to reduce the false-positives of formal and informal settlements. The accuracy result of subset 1 was used as a benchmark for the comparison with the accuracies of subset 2 and 3.

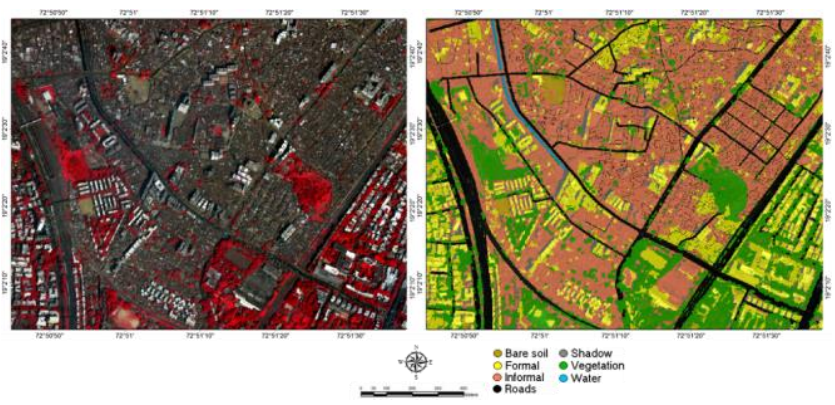

Figure 3: Image Subset 1 (left) and classification result (right)

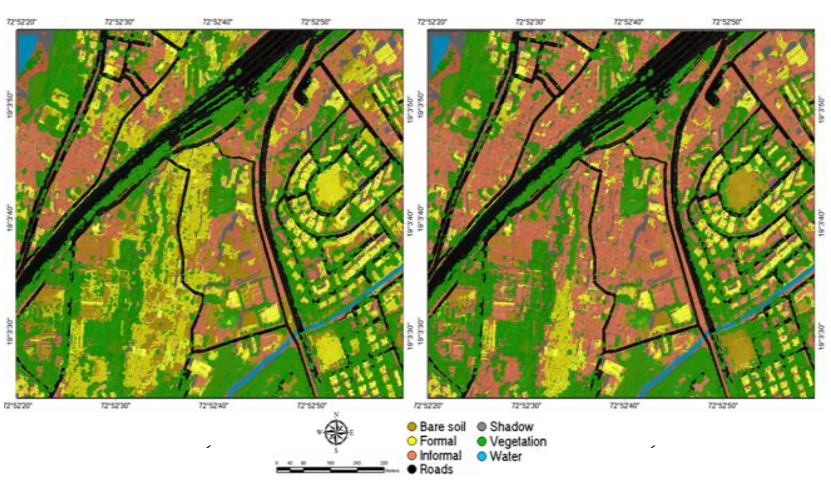

Figure 4. Subset 2 before (left) and after adaption (right)
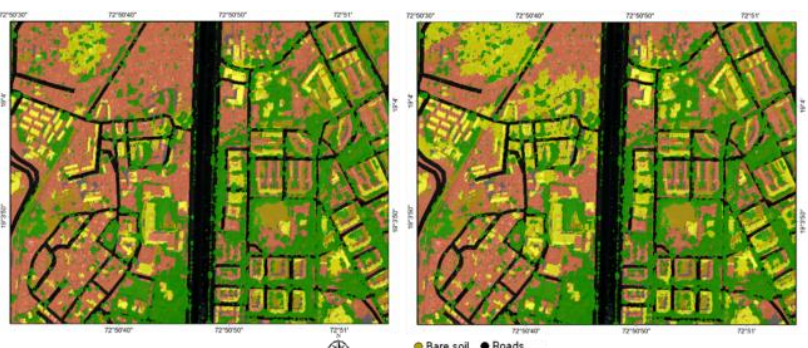

.

Figure 5. Subset 3 before (left) and after adaption (right)

Next, the same rule set was applied on subset 2 and 3 (Figure 4 and 5) and accuracies were measured. The overall accuracies before adaptation for subset 2 and 3 were $79 \%$ and $82 \%$ respectively. Thus for both subsets the accuracies were lower than that of subset 1 . This required adapting the parameters to improve the classification accuracies to be similar or better than for subset 1. After adapting the rule sets, the overall classification accuracies for subset 2 and subset 3 were $85 \%$ and $86 \%$, while for the informal settlements class, the accuracies were $82 \%$ and $86 \%$ respectively. Henceforth, we considered not only qualities but also the deviation of relative change of membership functions in evaluating the robustness of rule sets.

\subsection{Robustness Measurement of Rule Set}

The classification quality was analysed via, completeness, correctness and a quality percentage (equation 3-5). The 
classification quality of subset 1 was $52.4 \%$ and for subset 2 it was $5.6 \%$ which was very low in comparison (Table 2). The classification quality of subset 3 , however, was $58 \%$. Therefore, deviation of relative change of the membership function was considered for subset 2 but not for subset 3 .

Table 2: Classification qualities

\begin{tabular}{|c|c|c|c|c|}
\hline & Subsets & $\begin{array}{c}\text { Completeness } \\
\left(\mathbf{C}_{1}\right)\end{array}$ & $\begin{array}{c}\text { Correctness } \\
\left(\mathbf{C}_{2}\right)\end{array}$ & $\begin{array}{c}\text { Quality percentage } \\
(\mathrm{QP})\end{array}$ \\
\hline  & Subset 1 & $61.29 \%$ & $78.28 \%$ & $52.38 \%$ \\
\hline \multirow{2}{*}{ 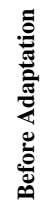 } & Subset 2 & $58.04 \%$ & $5.88 \%$ & $5.64 \%$ \\
\hline & Subset 3 & $61.02 \%$ & $91.78 \%$ & $57.86 \%$ \\
\hline \multirow{2}{*}{  } & Subset 2 & $65.86 \%$ & $70.90 \%$ & $51.85 \%$ \\
\hline & Subset 3 & $63.61 \%$ & $80.69 \%$ & $55.21 \%$ \\
\hline
\end{tabular}

After measuring the quality criterion the deviation of relative change of the membership function was calculated. Equation 6 provided the results of deviation for each parameter used in the class features. We found that the parameters of thematic attributes roads, GLCM red entropy and NDGR were found to be stable throughout the classification by achieving deviations below 0.5 in all subsets. The overall deviation $\left(\mathrm{d}_{1}\right)$ for subset 2 was 6.04 whereas deviation $\left(\mathrm{d}_{2}\right)$ for subset 3 after adaptation was 6.89. Using equation 7 , the robustness of the developed rule set is found to be 0.14 out of 1 .

\section{DISCUSSION}

The results of this research show that the employed spectral indices (NDNB and NDGR) have an important role in detecting informal settlements using VHR satellite images. In the study of Hamedianfar and Shafri (2015),these indices were employed to distinguish between roof and non-roof surfaces, while in this research they are used to distinguish between formal settlements, bare soil and informal settlements.

A limitation of this study is the use of non-random sampling frame. This was done because of the limited accessibility of informal settlements. In the adaption process, we observed that the performance of parameters dropped when the first parameter was optimized. For instance in the case of detecting formal settlements three OBIA parameters were used. The first parameter was the GLCMred entropy. After optimizing this parameter for classification, the remaining parameters showed problems. However, the parameter NDNB did not require much adaptation. For example, while trying to detect shadows using the parameter NDNB, it showed good potential for detecting formal settlements as well.

Estimation of stable parameters in different subsets was done by selecting image based parameters for which membership values below 0.50 were found in the different subsets. Using the membership function samples for the classification must be taken for each rule in order to generate the fuzzy membership function automatically in the class description rather than manually inserting the membership function type. Moreover, the fuzzy membership function plays an important role in incorporating local knowledge while developing the rule set.
The deviation of the rule set is also highly influenced by the selected scales. If all other parameters, such as changing classes, operators, connectors, rules and thresholds were included as additional conditions in measuring the deviations of the rule sets, then it might contribute to strengthen the identification of the stable parameters. For example, the deviation of relative change of membership function because of absence of the water class in subset 3 negatively impacted the robustness. The robustness of the rule set could be increased up to 0.62 when considering cases in which classification quality is close to the quality of the subset 1 and ignoring the deviation of relative change of the membership function.

\section{CONCLUSIONS}

In this study, local expert knowledge was used to produce a local adaptation of GSO for Mumbai, resulting in spatial, geometry and texture based indicators. Furthermore, we used spectral indices (NDRR and NDNB) as an important feature for extracting informal settlements. These spectral indices are specific to WV-2 satellite imagery with its very unique 8 bands. In our study, we have tested these indices in three subsets showing their relative robustness. However, we cannot generalise this beyond our study area. Using spatial, geometry, spectral and texture indices we found the classification accuracy was less in subset 2 and 3 as compared to that of subset 1 . The addition of thematic layers (e.g. roads) did help in improving the segmentation quality as well as the classification accuracy.

To evaluate the robustness of the initial rule set, we used two criteria i.e. the classification quality and the deviation of relative change of the membership functions. We found that the degree of robustness is 0.14 (out of 1 ) which is considerably similar to earlier studies (e.g. Hofmann et al., 2011). For future research, other criteria in addition to deviation could allow more insights on robustness. In this study, parameters such as NDGR of spectral index and GLCM texture are found to be most stable in all subsets and therefore these parameters can be used to strengthen the robustness in future research.

\section{ACKNOWLEDGEMENTS (OPTIONAL)}

We would also like to thank Mr. Ronald Soubam and Mr. Kakchingtabam Lenin Sharma for their support during the fieldwork.

\section{REFERENCES}

Drăguţ, L., Tiede, D., \& Levick, S. R. (2010). ESP: a tool to estimate scale parameter for multiresolution image segmentation of remotely sensed data. International Journal of Geographical Information Science, 24(6), 859-871. doi: 10.1080/13658810903174803

Ebert, A., Kerle, N., \& Stein, A. (2009). Urban social vulnerability assessment with physical proxies and spatial metrics derived from air- and spaceborne imagery and GIS data. Nat. Hazards, 48(2), 275-294. doi: 10.1007/s11069-008-9264-0

Government of India. (2015). Population Census 2011. Retrieved 07-06-2016, from http://www.census2011.co.in/

Hamedianfar, A., \& Shafri, H. Z. M. (2015). Detailed intraurban mapping through transferable OBIA rule sets using WorldView-2 very-high-resolution satellite images. Int. J. Remote Sens., 36(13), 3380-3396. doi: 10.1080/01431161.2015.1060645 
Hofmann, P. (2014). Defining robustness measures for OBIA framework: A case study for detecting informal settlements. In Q. Weng (Ed.), Global Urban Monitoring and Assessment through Earth Observation (pp. 303-324). Boca Raton, FL, USA: CRC Press.

Hofmann, P., Blaschke, T., \& Strobl, J. (2011). Quantifying the robustness of fuzzy rule sets in object-based image analysis. Int. J. Remote Sens., 32(22), 7359-7381. doi: 10.1080/01431161.2010.523727

Hofmann, P., Strobl, J., Blaschke, T., \& Kux, H. (2008). Detecting informal settlements from QuickBird data in Rio de Janeiro using an object based approach. In T. Blaschke, S. Lang \& G. Hay (Eds.), Object-Based Image Analysis (pp. 531-553). Berlin|Heidelberg, Germany: Springer.

Jinguo, Y., \& Zheng, N. (2008, 30 June -2 July 2008). Evaluation of atmospheric correction using FLAASH. Paper presented at the International Workshop on Earth Observation and Remote Sensing Applications, 2008. EORSA 2008, Beijing (China).

Kit, O., Lüdeke, M., \& Reckien, D. (2012). Texture-based identification of urban slums in Hyderabad, India using remote sensing data. App. Geogr., 32(2), 660667. http://dx.doi.org/10.1016/j.apgeog.2011.07.016

Kohli, D., Sliuzas, R. V., Kerle, N., \& Stein, A. (2012). An ontology of slums for image-based classification. Computers Environment and Urban Systems, 36(2), 154-163.

Kohli, D., Stein, A., Sliuzas, R. V., \& Kerle, N. (2015). Identifying and Classifying Slum Areas Using Remote Sensing. (PhD), University of Twente Faculty of GeoInformation and Earth Observation (ITC), Enschede, The Netherlands. Retrieved from http://www.itc.nl/library/papers_2015/phd/kohli.pdf

Kohli, D., Warwadekar, P., Kerle, N., Sliuzas, R., \& Stein, A. (2013). Transferability of object-oriented image analysis methods for slum identification. Remote Sens., 5(9), 4209-4228.

Kuffer, M., Pfeffer, K., \& Sliuzas, R. (2016). Slums from Space-15 Years of Slum Mapping Using Remote Sensing. Remote Sens., 8(6), 455.

Kuffer, M., Pfeffer, K., Sliuzas, R., \& Baud, I. (2016). Extraction of slum areas from VHR imagery using GLCM variance. IEEE J. Sel. Top. Appl. Earth Observ. and Remote Sens., 9(5), 1830-1840. doi: 10.1109/JSTARS.2016.2538563

Montaghi, A., Larsen, R., \& Greve, M. H. (2013). Accuracy assessment measures for image segmentation goodness of the Land Parcel Identification System (LPIS) in Denmark. Remote Sens. Lett., 4(10), 946955. doi: 10.1080/2150704X.2013.817709

Netzband, M., \& Rahman, A. (2009 ). Physical characterisation of deprivation in cities. How can remote sensing help to profile poverty (slum dwellers) in the megacity of Delhi/India? Paper presented at the Proceedings of the IEEE Joint Urban Remote Sensing Event, Shanghai, China. <Go to ISI > //WOS:000270972300186

Nolan, L. B. (2015). Slum Definitions in Urban India: Implications for the Measurement of Health Inequalities. Popul. Dev. Rev., 41(1), 59-84. doi: 10.1111/j.1728-4457.2015.00026.x

Subbaraman, R., Nolan, L., Shitole, T., Sawant, K., Shitole, S., Sood, K., . . . Patil-Deshmukh, A. (2014). The psychological toll of slum living in Mumbai, India: A mixed methods study. Soc. Sci. Med., 119, 155-169. doi:

http://dx.doi.org/10.1016/j.socscimed.2014.08.021

UN-Habitat. (2010). State of the world's cities 2010- 2011: Bridging the urban divide. Nairobi. 